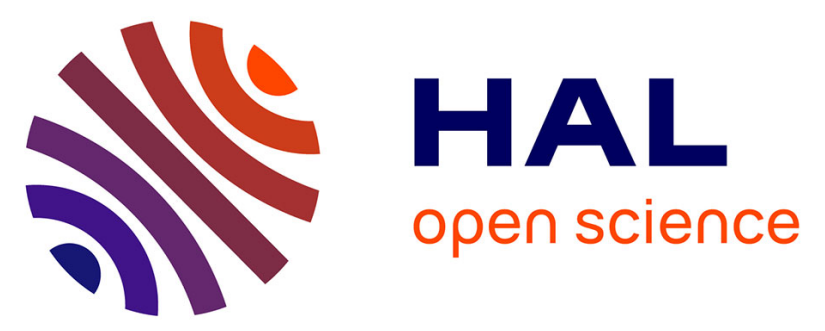

\title{
Surface relief gratings induced by pulsed laser irradiation in low glass-transition temperature azopolysiloxanes
}

\author{
Victor Damian, Elena Resmerita, Iuliana Stoica, Constanta Ibanescu, Liviu
}

Sacarescu, Licinio Rocha, Nicolae Hurduc

\section{- To cite this version:}

Victor Damian, Elena Resmerita, Iuliana Stoica, Constanta Ibanescu, Liviu Sacarescu, et al.. Surface relief gratings induced by pulsed laser irradiation in low glass-transition temperature azopolysiloxanes. Journal of Applied Polymer Science, 2014, 131 (24), pp.41015. 10.1002/app.41015 . cea-01831791

\section{HAL Id: cea-01831791 https://hal-cea.archives-ouvertes.fr/cea-01831791}

Submitted on 20 May 2019

HAL is a multi-disciplinary open access archive for the deposit and dissemination of scientific research documents, whether they are published or not. The documents may come from teaching and research institutions in France or abroad, or from public or private research centers.
L'archive ouverte pluridisciplinaire HAL, est destinée au dépôt et à la diffusion de documents scientifiques de niveau recherche, publiés ou non, émanant des établissements d'enseignement et de recherche français ou étrangers, des laboratoires publics ou privés. 


\section{Applied Polymer \\ Special Issue: Polymers for Microelectronics

\author{
Guest Editors: Dr Brian Knapp (Promerus LLC) and \\ Prof. Paul A. Kohl (Georgia Institute of Technology)
}

\section{EDITORIAL}

Polymers for Microelectronics

B. Knapp and P. A. Kohl, J. Appl. Polym. Sci. 2014, DOI: 10.1002/app.41233

\section{REVIEW}

Negative differential conductance materials for flexible electronics

A. Nogaret, J. Appl. Polym. Sci. 2014, DOI: 10.1002/app.40169

\section{RESEARCH ARTICLES}

Generic roll-to-roll compatible method for insolubilizing and stabilizing conjugated active layers based on low energy electron irradiation
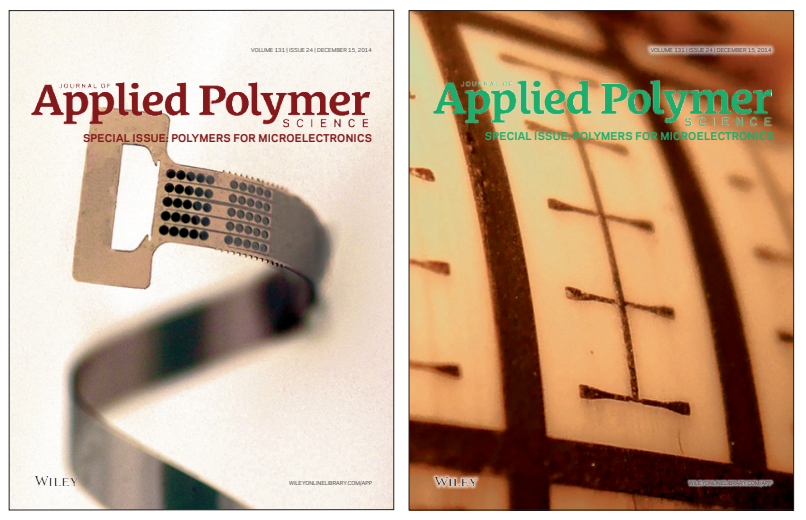
M. Helgesen, J. E. Carlé, J. Helt-Hansen, A. Miller, and F. C. Krebs, J. Appl. Polym. Sci. 2014, DOI: 10.1002/app.40795

Selective etching of polylactic acid in poly(styrene)-block-poly(D,L)lactide diblock copolymer for nanoscale patterning C. Cummins, P. Mokarian-Tabari, J. D. Holmes, and M. A. Morris, J. Appl. Polym. Sci. 2014, DOI: 10.1002/app.40798

Preparation and dielectric behavior of polyvinylidene fluoride composite filled with modified graphite nanoplatelet P. Xie, Y. Li, and J. Qiu, J. Appl. Polym. Sci. 2014, DOI: 10.1002/app.40229

Design of a nanostructured electromagnetic polyaniline-Keggin iron-clay composite modified electrochemical sensor for the nanomolar detection of ascorbic acid

R. V. Lilly, S. J. Devaki, R. K. Narayanan, and N. K. Sadanandhan, J. Appl. Polym. Sci. 2014, DOI: 10.1002/app.40936

Synthesis and characterization of novel phosphorous-silicone-nitrogen flame retardant and evaluation of its flame retardancy for epoxy thermosets

Z.-S. Li, J.-G. Liu, T. Song, D.-X. Shen, and S.-Y. Yang, J. Appl. Polym. Sci. 2014, DOI: 10.1002/app.40412

Electrical percolation behavior and electromagnetic shielding effectiveness of polyimide nanocomposites filled with carbon nanofibers L. Nayak, T. K. Chaki, and D. Khastgir, J. Appl. Polym. Sci. 2014, DOI: 10.1002/app.40914

Morphological influence of carbon modifiers on the electromagnetic shielding of their linear low density polyethylene composites B. S. Villacorta and A. A. Ogale, J. Appl. Polym. Sci. 2014, DOI: 10.1002/app.41055

Electrical and EMI shielding characterization of multiwalled carbon nanotube/polystyrene composites

V. K. Sachdev, S. Bhattacharya, K. Patel, S. K. Sharma, N. C. Mehra, and R. P. Tandon, J. Appl. Polym. Sci. 2014, DOI: 10.1002/app.40201

Anomalous water absorption by microelectronic encapsulants due to hygrothermal-induced degradation

M. van Soestbergen and A. Mavinkurve, J. Appl. Polym. Sci. 2014, DOI: 10.1002/app.41192

Design of cyanate ester/azomethine/ $\mathrm{ZrO}_{2}$ nanocomposites high-k dielectric materials by single step sol-gel approach M. Ariraman, R. Sasi Kumar and M. Alagar, J. Appl. Polym. Sci. 2014, DOI: 10.1002/app.41097

Furan/imide Diels-Alder polymers as dielectric materials

R. G. Lorenzini and G. A. Sotzing, J. Appl. Polym. Sci. 2014, DOI: 10.1002/app.40179

High dielectric constant polyimide derived from 5,5'-bis[(4-amino) phenoxy]-2,2'-bipyrimidine

X. Peng, Q. Wu, S. Jiang, M. Hanif, S. Chen, and H. Hou, J. Appl. Polym. Sci. 2014, DOI: 10.1002/app.40828

The influence of rigid and flexible monomers on the physical-chemical properties of polyimides

T. F. da Conceição and M. I. Felisberti, J. Appl. Polym. Sci. 2014, DOI: 10.1002/app.40351 


\title{
Applied Polymer
}

\section{Special Issue: Polymers for Microelectronics}

\author{
Guest Editors: Dr Brian Knapp (Promerus LLC) and \\ Prof. Paul A. Kohl (Georgia Institute of Technology)
}

Development of polynorbornene as a structural material for microfluidics and flexible BioMEMS

A. E. Hess-Dunning, R. L. Smith, and C. A. Zorman, J. Appl. Polym. Sci. 2014, DOI: 10.1002/app.40969

A thin film encapsulation layer fabricated via initiated chemical vapor deposition and atomic layer deposition

B. J. Kim, D. H. Kim, S. Y. Kang, S. D. Ahn, and S. G. Im, J. Appl. Polym. Sci. 2014, DOI: 10.1002/app.40974

Surface relief gratings induced by pulsed laser irradiation in low glasstransition temperature azopolysiloxanes

V. Damian, E. Resmerita, I. Stoica, C. Ibanescu, L. Sacarescu, L. Rocha, and
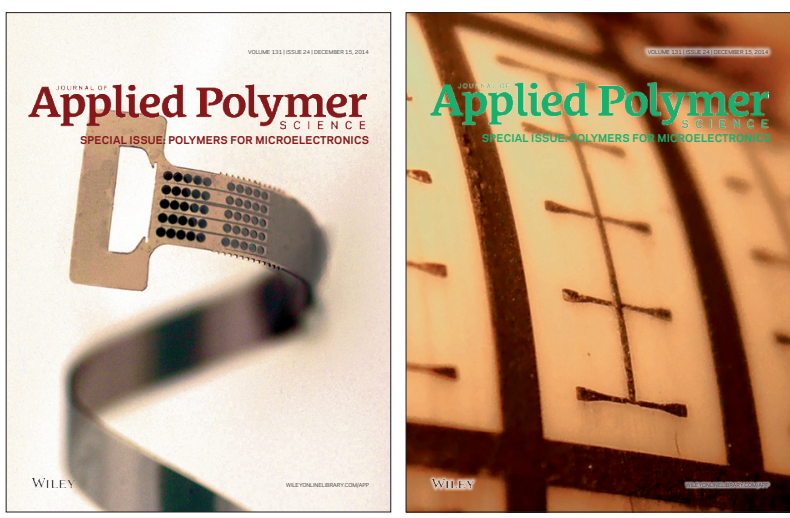

N. Hurduc, J. Appl. Polym. Sci. 2014, DOI: 10.1002/app.41015

Polymer-based route to ferroelectric lead strontium titanate thin films

M. Benkler, J. Hobmaier, U. Gleißner, A. Medesi, D. Hertkorn, and T. Hanemann, J. Appl. Polym. Sci. 2014, DOI: 10.1002/app.40901

The influence of dispersants that contain polyethylene oxide groups on the electrical resistivity of silver paste T. H. Chiang, Y.-F. Chen, Y. C. Lin, and E. Y. Chen, J. Appl. Polym. Sci. 2014, DOI: 10.1002/app.41183

Quantitative investigation of the adhesion strength between an SU-8 photoresist and a metal substrate by scratch tests X. Zhang, L. Du, and M. Zhao, J. Appl. Polym. Sci. 2014, DOI: 10.1002/app.41108

Thermodynamic and kinetic aspects of defectivity in directed self-assembly of cylinder-forming diblock copolymers in laterally confining thin channels

B. Kim, N. Laachi, K. T. Delaney, M. Carilli, E. J. Kramer, and G. H. Fredrickson, J. Appl. Polym. Sci. 2014, DOI: 10.1002/app.40790 


\title{
Applied Polymer
}

\section{Surface Relief Gratings Induced by Pulsed Laser Irradiation in Low Glass-Transition Temperature Azopolysiloxanes}

\author{
Victor Damian, ${ }^{1}$ Elena Resmerita, ${ }^{2}$ Iuliana Stoica, ${ }^{3}$ Constanta Ibanescu, ${ }^{2}$ Liviu Sacarescu, ${ }^{3}$ \\ Licinio Rocha, ${ }^{4}$ Nicolae Hurduc ${ }^{2}$ \\ ${ }^{1}$ National Institute for Laser, Plasma, and Radiation Physics, 409 Atomistilor Street, Bucharest-Magurele, Romania \\ ${ }^{2}$ Department of Natural and Synthetic Polymers, Gheorghe Asachi Technical University of lasi, 73 Professor Dimitrie Mangeron \\ Street, 700050 lasi, Romania \\ ${ }^{3}$ Petru Poni Institute of Macromolecular Chemistry, 41A Aleea Grigore Ghica Voda, 700487 lasi, Romania \\ ${ }^{4}$ Commission for Atomic Energy and Alternative Energies (CEA), Institute for Smart Digital Systems Saclay (LIST) Saclay, \\ Laboratoire Capteurs et Architectures Électroniques, F-91191 Gif-sur-Yvette Cedex, France \\ Correspondence to: L. Rocha (E-mail: licinio.rocha@cea.fr) and N. Hurduc (E-mail: nhurduc@ch.tuiasi.ro)
}

\begin{abstract}
Polymers capable of generating surface relief gratings (SRGs) were studied intensively in the last period for their applications in hot research areas, such as data storage, solar energy conversion, plasmonics, and biology. In the case of azopolymers, SRGs can be generated by two main procedures: pulsed or continuous laser irradiation. In this article, we discuss the possibility of obtaining stable SRGs with azopolysiloxanes with low glass-transition temperature values, depending on the illumination type. These studies evidenced that the polymer chemical structure had a strong influence on the SRG stability in time. For the unsubstituted azobenzene, unstable surfaces resulted, whereas for the substituted azo groups stable reliefs were obtained. A parallel discussion between the pulsed and continuous irradiation techniques and structuration mechanisms is given. The operational conditions strongly affected the relief quality when the pulsed laser irradiation method was used. () 2014 Wiley Periodicals, Inc. J. Appl. Polym. Sci. 2014, $131,41015$.
\end{abstract}

KEYWORDS: nanostructured polymers; stimuli-sensitive polymers; supramolecular structures

Received 8 March 2014; accepted 19 May 2014

DOI: 10.1002/app.41015

\section{INTRODUCTION}

In 1995, two independent research groups, Natansohn et al. ${ }^{1}$ and Kumar et al., ${ }^{2}$ reported one of the most interesting behavior of azopolymers: the capacity to generate surface relief gratings (SRGs) as a consequence of light irradiation through an interference pattern. This behavior is a consequence of the trans-cistrans isomerization processes of the azobenzene groups, which are either linked to a polymeric chain, ${ }^{1-5}$ or part of azo-dyedoped polymers (guest-host systems). ${ }^{6-8}$ Usually, SRGs are generated with laser interference systems or interference masks through continuous or pulsed laser irradiation. Although continuous laser irradiation systems have been given special attention, ${ }^{1-11}$ the pulsed laser method has been investigated much less. ${ }^{12-17}$ Although many research groups have intensively studied the processes responsible for the SRG formation, the underlying mechanism has remained unclear until now. SRG inscription is supposed to generate alternatively illuminated and nonilluminated regions on azopolymeric film surfaces. In the case of continuous laser irradiation, the material starts to migrate from the illuminated regions to the dark ones, ${ }^{18}$ even if the glass-transition temperature $\left(T_{g}\right)$ value of the polymer significantly exceeds the experimental conditions (usually $20-25^{\circ} \mathrm{C}$ ). Several models have been proposed, including the isomerization pressure, ${ }^{19}$ the gradient electric force, ${ }^{20}$ the permittivity gradient, ${ }^{21}$ the asymmetric diffusion (migration), ${ }^{22,23}$ the mean-field model, ${ }^{24}$ the theory of light-induced deformation, ${ }^{25}$ the cage-breaking model, ${ }^{26}$ and the statistical model based on fundamental molecular dipole; ${ }^{27}$ none of them have succeeded in comprehensively explaining the mass displacement. Quite recently, our group suggested a new approach for the formation of SRG mechanism based on multiple processes taking place in parallel, with one or the other being dominant as a function of the chemical structure and operational conditions: (1) polymer photofluidization in the illuminated regions, (2) mass displacement from illuminated to the dark regions, and (3) inverse mass displacement, from the dark regions to the illuminated regions. ${ }^{28}$

In a comparison with the continuous laser method, additional parameters have to be taken into account for pulsed laser 

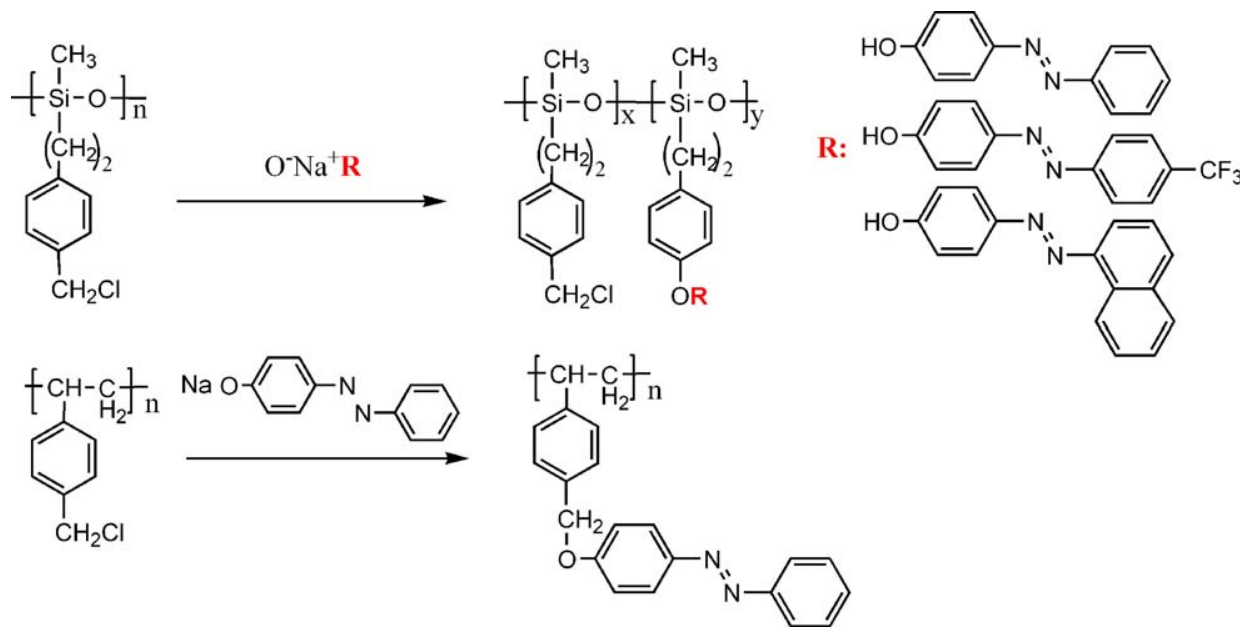

Scheme 1. Polymer synthesis routes. [Color figure can be viewed in the online issue, which is available at www.interscience.wiley.com.]

irradiation. Because of the very short irradiation times (nanoseconds/picoseconds) used in the pulsed mode as compared with the continuous one (minutes), a different mechanism of surface nanostructuration is expected. In the case of pulsed laser irradiation, a very fast chain reorganization process can be expected, induced by the azobenzene dipole orientation because of the interaction of the laser polarized light. This reorganization process at a supramolecular level takes place even in the case of polymers with very high $T_{g}$ values, such as azopolyimides, ${ }^{29}$ where one laser pulse (6 ns) is enough to generate an SRG. The possibility of obtaining SRGs by laser pulsed irradiation in azopolysiloxanes was evident in our previous studies. ${ }^{30,31}$ Although, for the case of continuous laser irradiation, the peaks corresponding to the sinusoidal surface relief are present in the dark regions, for the pulsed lasers, the peaks are positioned as a function of laser fluence. Below a threshold fluence value, the peaks are present in the illuminated regions, and above this threshold, trenches are formed in the illuminated regions. ${ }^{13}$ Film surface structuration is accompanied by a diminution of the material density; in the surface relief domains, the density has lower values compared to that in the pristine films. ${ }^{12}$

In the beginning, the SRG imprinting technique using laser irradiation was focused on the fields of data storage and holography, ${ }^{11,32}$ but more recently, new biological applications of the azopolymers were reported (cell cultures, artificial muscles, photosensitive viruses, and proteins). ${ }^{32-39}$ One of the most interesting applications of SRG azopolymers is their use as cell culture supports. The ability of cells to respond to different signals generated by the extracellular matrix has been studied intensively in recent years, ${ }^{40,41}$ and much attention has been paid to the understanding of these phenomena. Among a variety of materials used as support for cell cultures, azopolymers distinguish themselves by certain advantages, such as their one-step procedure for surface nanostructuration (with no chemical reaction) and the complex design of the surface relief, which is impossible to obtain by classical lithography. ${ }^{9}$ Taking into consideration that different structuration mechanisms are specific to each type of laser irradiation method (continuous or pulsed), the expected cell response to the substrate will be manifold and related to the SRG preparation technique.

In this study, the possibility of obtaining stable SRGs in azopolysiloxanes with pulsed laser irradiation was investigated. When the polymeric chains were grafted with unsubstituted azobenzene groups, surface relief instability was observed; $1 \mathrm{~h}$ after inscription, the relief surface began to disappear. If azonaphthalene or trifluoromethyl $\left(\mathrm{CF}_{3}\right)$-parasubstituted azobenzene groups were connected in the polysiloxanic chain, the SRGs remained stable. A very high sensitivity of the relief geometric parameters was observed in the case of pulsed laser irradiation as a function of the operational parameters (laser fluence and pulse number). A parallel discussion between the characteristics of SRGs obtained by pulsed or continuous wave $(\mathrm{CW})$ laser irradiation was effectuated. When the CW laser irradiation was used, we obtained stable SRGs, even in the case of the polysiloxane substituted with azobenzene; this suggested the idea that different organization mechanisms took place in the film as a function of the laser irradiation technique.

\section{EXPERIMENTAL}

The starting polysiloxane, which contained chlorobenzyl groups in the side chain, was obtained by a two-step reaction, which started from dichloro(4-chloromethyl-phenylethyl)methylsilane (produced by ABCR GmbH \& $\mathrm{Co}$ ). A hydrolysis reaction took place in the first step, and this resulted in a mixture of linear and cyclic oligomers. The second step supposed a cationic equilibration in the presence of trifluoromethanesulfonic acid and 1,3divinyl-1,1,3,3-tetramethyldisiloxane (Aldrich) as a chain blocker; this resulted in the formation of linear polymers [number-average molecular weight $\left.\left(M_{n}\right) \approx 6000\right]$. The polysiloxanes were then modified with different azophenols with an $\mathrm{SN}_{2}$ reaction in dimethyl sulfoxide (Scheme 1). Details concerning the polymer synthesis and characterization were previously reported. ${ }^{42,43}$

The modification of poly(chloromethyl styrene) (PCMS) with 4(phenyl-azophenol) was effectuated under similar conditions, as in the case of the polysiloxane. The azopolymeric films were prepared by the spin-coating method with 1,1,2-trichloroetane as the solvent. 


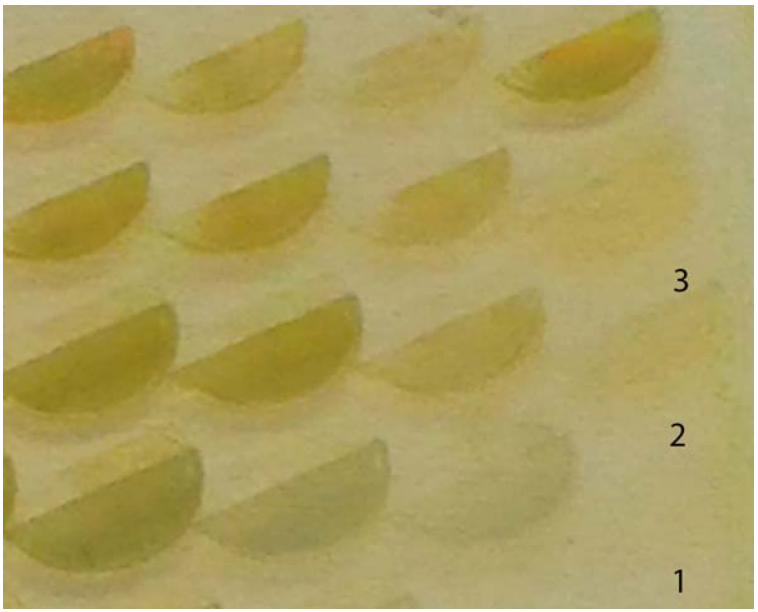

Figure 1. Picture of the different SRG regions (corresponding to sample 1) generated on the film surface. The relief instability can be observed from the disappearance of SRGs (points 1-3). [Color figure can be viewed in the online issue, which is available at wileyonlinelibrary.com.]

The experimental setup used for pulsed SRG inscription was a Lloyd interferometric design (Figure S1 in the Supporting Information). As a radiation source for the setup, we used a pulsed Nd:YAG laser, working on its third harmonic at $355 \mathrm{~nm}$ with a pulse length of $6 \mathrm{~ns}$ and a repetition rate of $10 \mathrm{~Hz}$ and having a 0.6-mrad divergence and a 6-mm diameter. The laser energy was varied in the domain $0.6-130 \mathrm{~mJ}$ and was permanently monitored with an energy meter. The setup ensured that the fluence on the probe was far from the ablation threshold of the polymers. To obtain a small irradiated area, we used a set of aperture stops. The Lloyd Mirror M accomplished the superposition of the two halves of the divergent beam to obtain the interference. Because of the circular form of the incident laser beam, the final interference field looked like that in Figure 1, with a fluence in the domain $2-20 \mathrm{~mJ} / \mathrm{cm}^{2}$. The results of two beams' interference is generally a sinusoidal grating, with a pitch around $2 \mu \mathrm{m}$ (Figure S2 in the Supporting Information). The morphological details for the SRGs obtained by the pulsed laser irradiation technique were visualized with a Solver Pro-M Scanning Probe Microscope (NT-MDT, Zelenograd, Russia) in atomic force microscopy (AFM) configuration. To minimize the convolution effects, rectangular silicon cantilevers NSG10 (NTMDT, Russia) with resonance frequencies ranging from 250 to
$300 \mathrm{kHz}$ and tips of high aspect ratio were used. All images were acquired in air at room temperature $\left(22^{\circ} \mathrm{C}\right)$ in tapping mode with a scan rate frequency of $0.6 \mathrm{~Hz}$. For image acquisition and processing, Nova version 1.26.0.1443 for Solver software was used.

In the case of CW SRG inscription, the polymer films were illuminated with an interference pattern produced by the superposition of two coherent beams incident symmetrically onto the film with respect to the film surface normal direction (Figure S3 in the Supporting Information). The beam, delivered by a 488-nm-wavelength laser diode, was incident to a beam splitter, and the resulting beams were superposed onto the film after reflection onto two mirrors. The resulting interference pattern presented a sinusoidal modulation of the intensity along the polymer surface. The intensity in both beams was adjusted with the optical densities being equal. An average intensity of 180 $\mathrm{mW} / \mathrm{cm}^{2}$ was used for the experiments, and the beam polarization was set on the incidence plane, that is, perpendicular to the interference pattern fringes. A 633-nm-wavelength heliumneon laser was used to record the evolution of the first-order diffraction efficiency during the film illumination. In the case of continuous laser irradiation, the surface modulations on the polymer films were performed with a PicoLE 5100 AFM supplied by Agilent Technologies. The AFM was driven in the acoustically driven mode (tapping) to minimize the interaction of the tip with the surface during the scan. Arrow NCR Silicon probes from Nanoworld with a nominal resonance frequency of $285 \mathrm{kHz}$ and a nominal spring constant of $42 \mathrm{~N} / \mathrm{m}$ were used. Images with a size of $512 \times 512$ pixels were generated with a scan rate frequency of $0.2-0.4 \mathrm{~Hz}$.

\section{RESULTS AND DISCUSSION}

Table I presents some characteristics of the synthesized polymers. The ultraviolet-visible absorption spectra are presented in the Supporting Information (Figure S4).

The first investigated polymer corresponded to sample 1 (Table I), a material having a relatively low $T_{g}$ value $\left(25^{\circ}\right)$. The pulsed laser fluence used in the relief imprinting process of sample 1 was situated in the rage $2.8-16.5 \mathrm{~mJ} / \mathrm{cm}^{2}$, and the pulse numbers were between 10 and 500. Surprisingly, SRGs were obtained, but $1 \mathrm{~h}$ after the inscription process, they began disappear. Because of the relief instability, it was not possible to use AFM to investigate the geometrical characteristics right after

Table I. Characteristics of the Synthesized Polymers

\begin{tabular}{|c|c|c|c|c|c|c|}
\hline $\begin{array}{l}\text { Sample } \\
\text { number }\end{array}$ & $\begin{array}{l}\text { Main-chain } \\
\text { structure }\end{array}$ & Substituent type & Sample code & $\begin{array}{l}\text { Substitution } \\
\text { degree (\%) }\end{array}$ & $M_{n}{ }^{a}$ & $\begin{array}{l}T_{g} \\
\left({ }^{\circ} \mathrm{C}\right)^{\mathrm{b}}\end{array}$ \\
\hline 1 & Polysiloxane & 4-Phenylazophenol & Azo-Psi & 80 & 10,200 & 25 \\
\hline 2 & Polysiloxane & 4-Phenylazophenol & Azo-Psi & 98 & 11,500 & 30 \\
\hline 3 & PCMS & 4-Phenylazophenol & Azo-PCMS & 98 & 12,600 & 87 \\
\hline 4 & Polysiloxane & 4-(Naphthalene-azo)-phenol & Naph-Azo-Psi & 90 & 11,700 & 47 \\
\hline 5 & Polysiloxane & 4-(4'-Trifluorometil-phenylazo)-phenol & $\mathrm{CF}_{3}-\mathrm{Azo}-\mathrm{Psi}$ & 80 & 10,800 & 45 \\
\hline
\end{tabular}

${ }^{a}$ From the NMR method.

${ }^{b}$ From the differential scanning calorimetry method. 
A
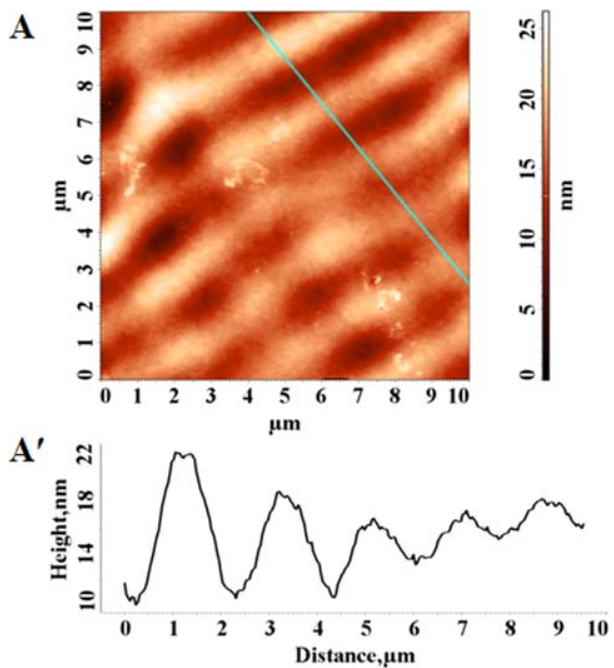

C

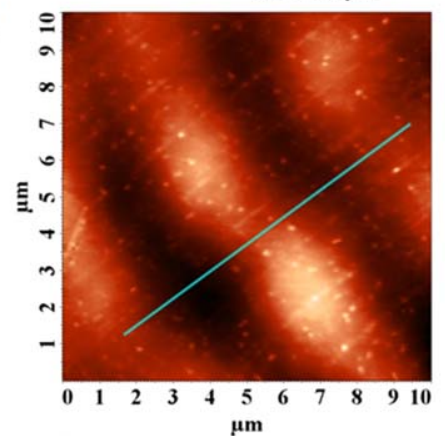

$\mathrm{C}^{\prime}$

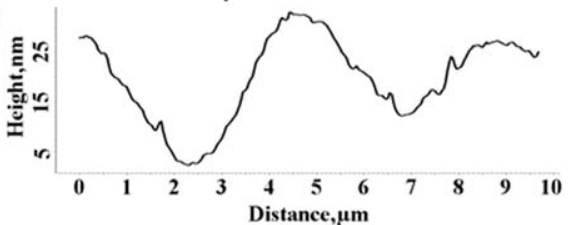

B
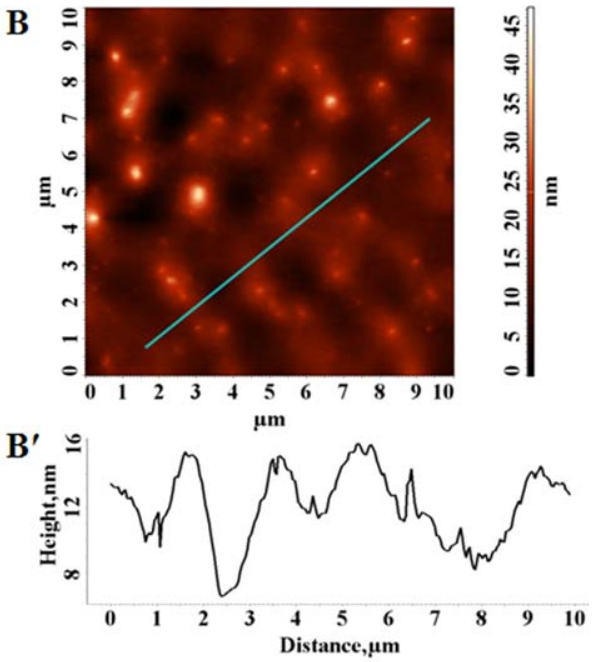

D
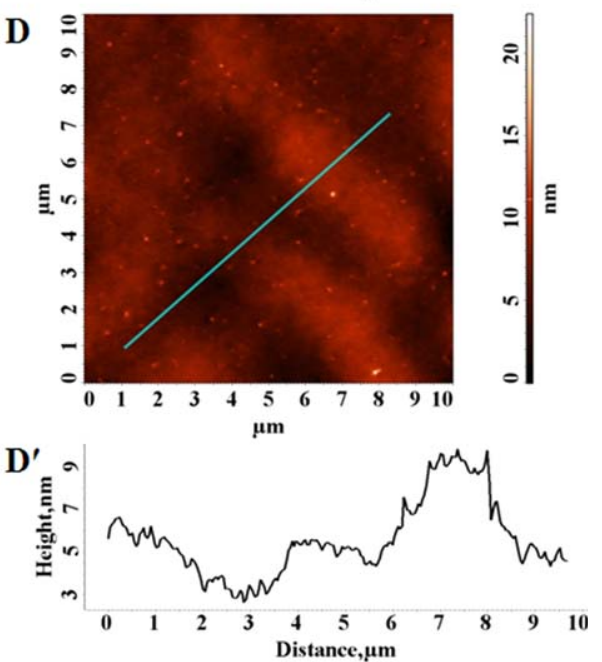

Figure 2. AFM images of the SRGs corresponding to sample 2 registered 14 days after inscription: (A) fluence of $14 \mathrm{~mJ} / \mathrm{cm}^{2}$ and $100 \mathrm{pulses}$, (B) fluence of $8.8 \mathrm{~mJ} / \mathrm{cm}^{2}$ and 100 pulses, (C) fluence of $13.8 \mathrm{~mJ} / \mathrm{cm}^{2}$ and 100 pulses, and (D) fluence of $11.8 \mathrm{~mJ} / \mathrm{cm}^{2}$ and 100 pulses. The film thicknesses were $(\mathrm{A}, \mathrm{B}) 500$ and $(\mathrm{C}, \mathrm{D}) 1000 \mathrm{~nm}$. [Color figure can be viewed in the online issue, which is available at wileyonlinelibrary.com.]

inscription. As shown in Figure 1, as a function of the moment of the laser imprinting and the irradiation conditions, the SRG domains disappeared one by one (at the points marked with 1 , 2, and 3).

The relief instability was not influenced by the film thickness, and for both thickness values investigated (500 and $1000 \mathrm{~nm}$ ), an erasing process was noticed. When we increased the substitution degree of the polysiloxane from 80 to $98 \%$ (sample 2), a $T_{g}$ value of $30^{\circ} \mathrm{C}$ was obtained. Even for this polymer with a $T_{g}$ situated above the ambient temperature, the relief instability was evident.

However, the surface relief was not completely erased and was probably as a function of the initial amplitude, with better or poorly defined SRGs being evident at the film surface even 2 weeks after inscriptions. For example, in Figure 2(A), traces of SRGs with 10-nm amplitudes and thus keeping the grating aspect, were observed on a 500-nm film thickness. When the laser fluence was diminished at $8.8 \mathrm{~mJ} / \mathrm{cm}^{2}$, even if the number of pulses was 200, the grating aspect disappeared, and only poor traces were evident [Figure 2(B)].
A similar behavior was evident for films that were $1000-\mathrm{nm}$ thick. As obvious from Figure 2(C), it was possible to observe traces of the gratings of $25-\mathrm{nm}$ amplitude on the surface. The decrease in the fluence value was reflected by the decrease in the grating amplitude to only $10 \mathrm{~nm}$ [Figure 2(D)].

This relief instability observed for Azo-Psi suggested the idea of different SRG formation mechanisms than were present in the case of the continuous laser irradiation technique. Previous studies of our group with the CW laser irradiation method evidenced a relief surface stability for more than 2 years for an Azo-Psi polymer (sample 2). However, it must be underlined that in the case of CW laser irradiation, the geometric relief characteristics were strongly influenced by the laser wavelength. As presented in Figure 3(A), with an argon-ion laser delivering a 365-nm-wavelength beam, only low SRG amplitude values (12 nm) were obtained. However, with a laser diode delivering a 488-nm-wavelength beam, amplitudes around $100 \mathrm{~nm}$ resulted [Figure 3(B)]. The modulations represented in the picture were obtained after $60 \mathrm{~min}$ of illumination. For the experiments, the 
A
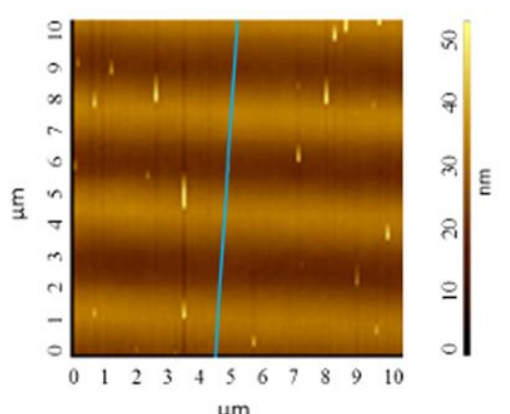

$\mu \mathrm{m}$

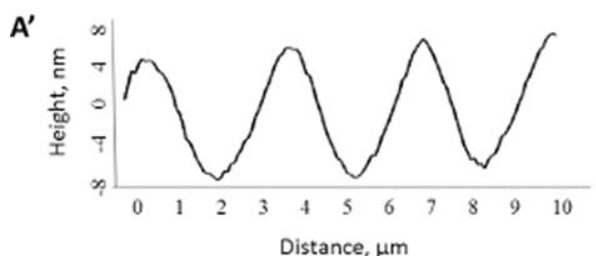

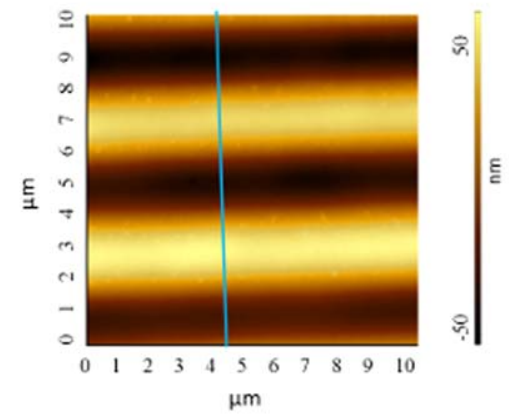

$B^{\prime}$

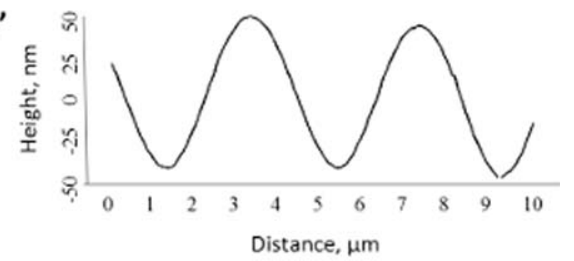

Figure 3. AFM images of the Azo-Psi film irradiated with (A) a 350-nm laser wavelength (relief amplitude $=12 \mathrm{~nm}$, SRG periodicity $=2.8 \mu \mathrm{m})$ and $(\mathrm{B})$ a 488-nm laser wavelength (relief amplitude $=96 \mathrm{~nm}$, SRG periodicity $=4 \mu \mathrm{m}$ ). [Color figure can be viewed in the online issue, which is available at wileyonlinelibrary.com.]

intensity was equalized in both interfering beams to optimize the interference contrast.

This might have been related to the efficiency of the trans-cistrans cycling depending on the excitation wavelength for this class of azobenzene molecules. In the case of the 488-nmwavelength excitation, both the trans and cis forms of the azobenzene molecule were excited; this favored the relaxation of the azobenzene molecule from its metastable cis state to the fundamental trans state. For an excitation in the UV absorption band $(355 \mathrm{~nm})$, the cis and trans isomer contents inside the material were different, with the cis isomer being in excess. This behavior suggests the idea that an excess of the cis isomer will be unfavorable to the mass-displacement mechanism.

A
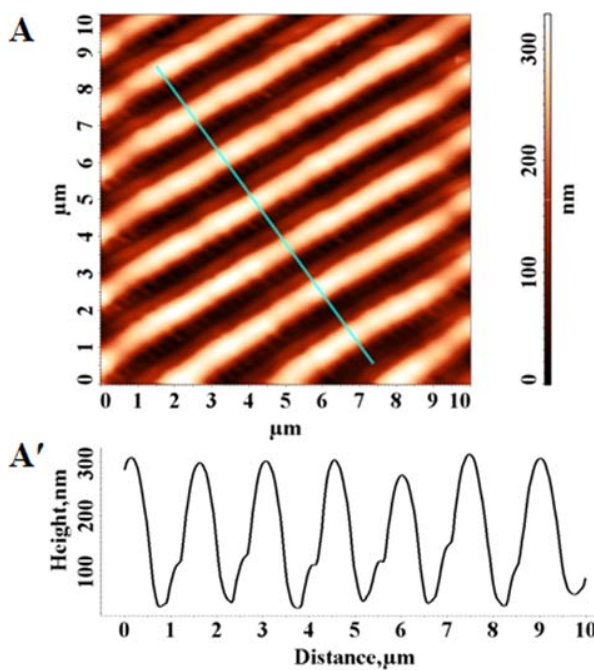

To estimate the influence of the $T_{g}$ value on the relief stability, a similar azopolymer with a rigid chain (sample 3 ) was irradiated with the pulsed laser system. This time, the surface relief was stable, and this enabled AFM evaluation. The AFM analyses reflected a strong influence of the operational conditions (laser fluence and number of pulses) on the relief quality. The best results were obtained when high values of laser fluence $\left(14-16 \mathrm{~mJ} / \mathrm{cm}^{2}\right)$ and a pulse number of around 200 were used (Figure 4).

A very interesting process of the SRG formation was evident as a function of the fluence value and pulse number. The AFM images evidenced a double-structuration process that was more evident at low fluence values. As shown in Figure 5(A) for a fluence value of $8.8 \mathrm{~mJ} / \mathrm{cm}^{2}$ and 50 pulses, a double-structuration

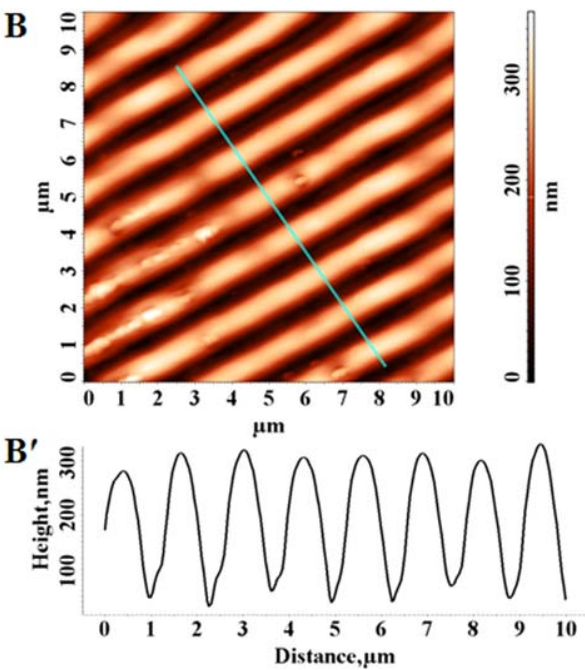

Figure 4. AFM images of the SRG corresponding to sample 3: (A) laser fluence of $14 \mathrm{~mJ} / \mathrm{cm}$ and 200 pulses (relief amplitude $=300 \mathrm{~nm}$ ) and (B) laser fluence of $16.5 \mathrm{~mJ} / \mathrm{cm}$ and 200 pulses (relief amplitude $=300 \mathrm{~nm}$ ). The film thickness was $500 \mathrm{~nm}$, and the SRG periodicity was $1.4 \mu \mathrm{m}$. [Color figure can be viewed in the online issue, which is available at wileyonlinelibrary.com.] 

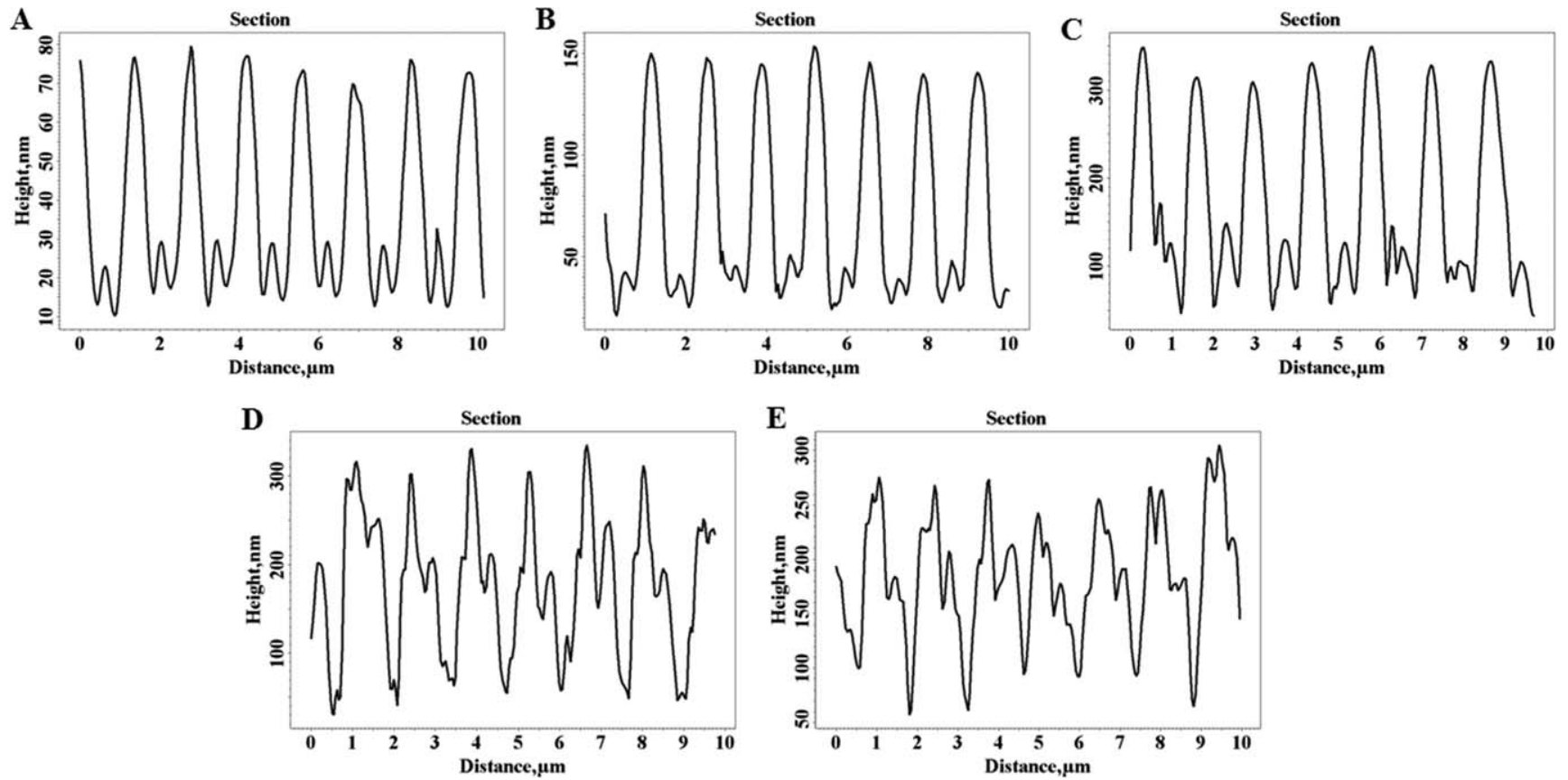

Figure 5. AFM images (cross sections) of the SRGs corresponding to sample 3 obtained with a fluence value of $8.8 \mathrm{~mJ} / \mathrm{cm}^{2}$ and different numbers of pulses: (A) 50, (B) 100, (C) 200, (D) 300, and (E) 500. The film thickness was $500 \mathrm{~nm}$, and the SRG periodicity was $1.4 \mu \mathrm{m}$.

process began, with two different amplitudes of the grooves being observed (at 70 and $25 \mathrm{~nm}$, respectively).

When the pulse number was increased to 100 [Figure 5(B)], the set of grooves having the higher value of the amplitude continued to grow (up to $150 \mathrm{~nm}$ ), with the other set of grooves maintaining a height of $25 \mathrm{~nm}$. At 300 pulses [Figure $5(\mathrm{C})]$, the first set reached the maximum amplitude value (ca.
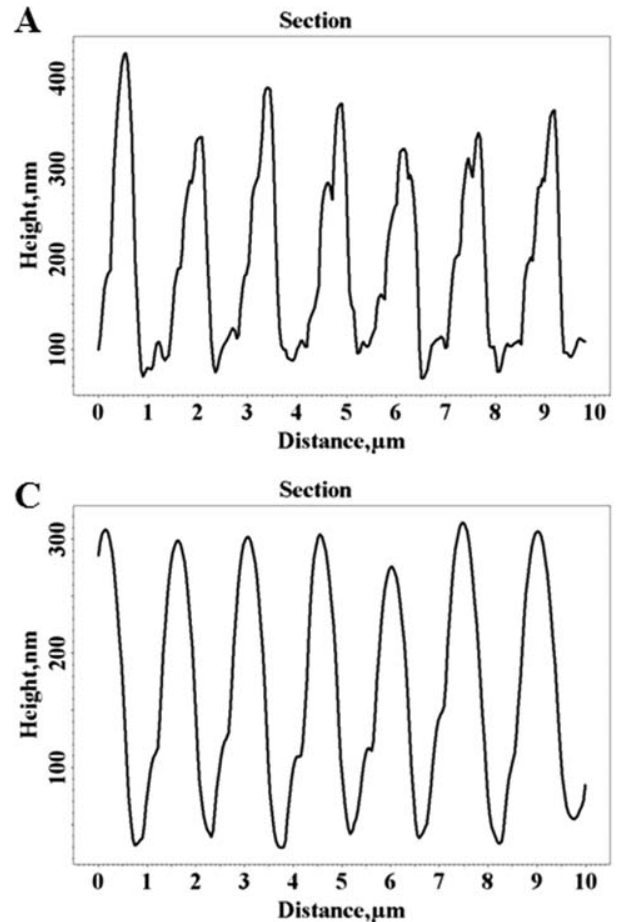

$300 \mathrm{~nm}$ ), and then, the second set of grooves began to increase and reached $100 \mathrm{~nm}$. If the fluence value was not enough high, the second set of grooves did not reach $300 \mathrm{~nm}$, even in the case of 500 pulses [Figure 5(E)]. In this situation, the final relief geometry was not homogeneous, and the grooves were split. A similar process took place in the case of a fluence value of $4.3 \mathrm{~mJ} / \mathrm{cm}^{2}$.
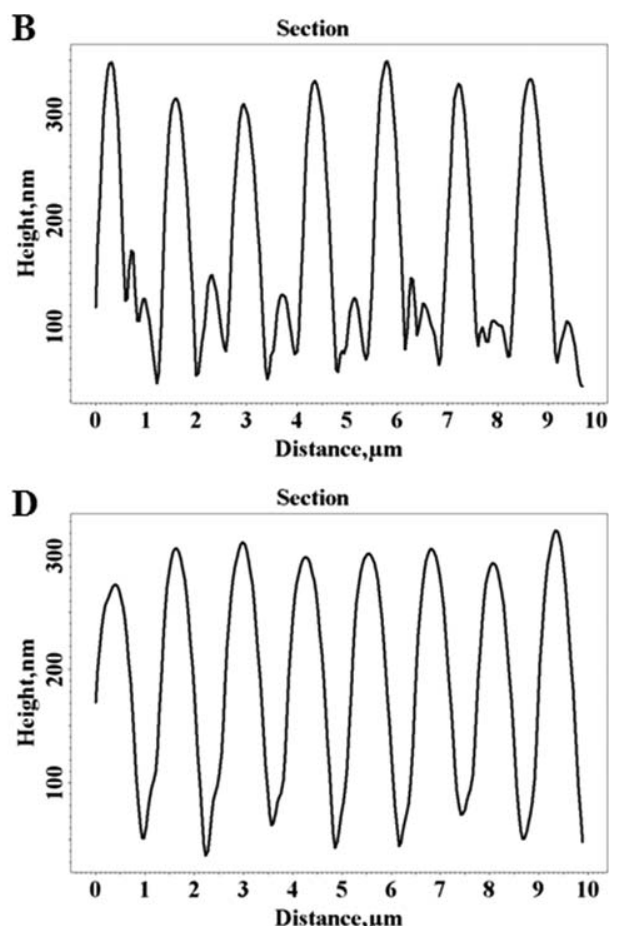

Figure 6. AFM images (cross sections) of the SRGs corresponding to sample 3 obtained with 200 pulses and different fluence values: (A) 4.3, (B) 8.8, (C) 14.2 , and (D) $16.5 \mathrm{~mJ} / \mathrm{cm}^{2}$. The film thickness was $500 \mathrm{~nm}$, and the SRG periodicity was $1.4 \mu \mathrm{m}$. 
The importance of the fluence value in the final relief quality is shown in Figure 6, where the number of pulses was maintained constant at 200. It was clear that when the fluence value was increased, the final relief quality was better, with the two sets of grooves merging.

The SRG increasing process suggested that the grooves were located in the illuminated areas of the interference pattern. In addition, the total value of the irradiation time situated in a scale of nanoseconds or microseconds suggested the idea that the massdisplacement process had only a secondary role or was perhaps totally absent. The presence of split grooves on the SRG was reported by other authors, too, but in the case of the CW technique. ${ }^{44-46}$ They explained the presence of split grooves by the existence of two different mechanisms of the structuration process.

Starting from these results, we propose a mechanism of SRG formation with pulsed laser irradiation based on a reordering process of the chains at the supramolecular level as a consequence of the trans-cis isomerization process. This idea was suggested by the very short irradiation times (situated on a scale of nanoseconds/microseconds) and by the wavelength of the laser used $(355 \mathrm{~nm})$. As shown in Figure S4 in the Supporting Information, the ultraviolet-visible spectra corresponding to Azo-Psi and Azo-PCMS, reflected strong absorption maxima in the domain of $350 \mathrm{~nm}$, which were attributed to the trans-cis isomerization (with the cis-trans absorption being present at $450 \mathrm{~nm}$ ). As a result, in a microsecond scale time irradiation, a high excess of the cis isomer content was expected and was reported for the trans one (the cis-trans relaxation was less probable in the absence of visible light, with the process taking place in a scale time of hours ${ }^{47}$ ). The trans-cis isomerization was not accomplished only by an important geometrical azomolecule modification but by a significant change in the dipolemoment value, which increased from 1.6 to $4.5 \mathrm{D} .^{46}$ As a result of these important changes of the azo molecules due to the isomerization process, significant modification at a supramolecular level was expected as well as material expansion.

This mechanism, based on the idea of the supramolecular reordering process, was in agreement with the SRG instability of the Azo-Psi as well. Because the $T_{g}$ values were close to the ambient temperatures corresponding to samples 1 and 2, the cis-trans relaxation process began immediately after the laser irradiation was turned off. As a result, the supramolecular ordering came back to the initial form of organization, along with the erasure of SRGs. For the Azo-PCMS sample, because of the higher value of $T_{g}$ compared with that of with Azo-Psi, the cis-trans relaxation process was not accomplished by the supramolecular reordering because of the stable glassy state.

Indeed, in the case of pulsed illumination, the film expansion increased the chain mobility and favored the surface erasure after excitation. For the CW illumination, where a mass transport was expected to occur, a densification of the material resulted; this restricted the chain mobility, and as a consequence, the material surface relaxed. The surface modulation was more stable in the last case.

It must be underlined that the pulsed laser irradiation technique could generate good results for the surface nanostructuration, even in the case of polymers having very high $T_{g}$ values. Previous studies developed in our group ${ }^{29,48}$ showed that for polyimides (with $T_{g}$ values situated above $200^{\circ} \mathrm{C}$ ), it was possible to obtain relief amplitudes of $300-400 \mathrm{~nm}$, even with $1-5$ pulses, but for a fluence value of $35 \mathrm{~mJ} / \mathrm{cm}^{2}$. These results were surprising when we took into consideration the relatively low content of the azo groups reported for the polymer chemical structure. AFM statistical analysis of the periodic three-dimensional nanogrooves was used to better understand the surface structuration process. ${ }^{49}$ This study showed that the groove depth increased, even 10s of times, when the incident fluence was increased (and the numbers of irradiation pulses were kept the same).

The problem of the surface relief stability or the azopolysiloxanic structure after the SRG imprinting was also evident, when in addition to the azophenols segment, donor/acceptor groups were linked on the polysiloxanic chains. ${ }^{50,51}$ Nevertheless, in these situations, the CW laser technique generated unstable surfaces, and the pulsed technique generated stable ones. This inverse behavior reflected the complexity of the surface structuration process, which was not the result only of a single mechanism. As demonstrated for CW laser irradiation, ${ }^{28,44}$ multiple parallel processes took place, with one or the other being dominant as a function of the polymer chemical structure.

Stable SRGs were also produced with polysiloxanes when the azonaphthalene group was used (sample 4, Table I). As in the case of the other samples, the surface relief quality was strongly influenced by the operational conditions. For the SRG inscription, a laser fluence situated in the domain of $8.3-29.3 \mathrm{~mJ} / \mathrm{cm}^{2}$ and a pulse number of 5-160 were used. In the case of NaphAzo-Psi, higher fluences were necessary, as reported to the previous samples, to obtain maximum amplitude values of the relief. The best results for the amplitude corresponded to a fluence of $29.3 \mathrm{~mJ} / \mathrm{cm}^{2}$ but a pulse number lower than 50 had to be used [relief amplitude $=400 \mathrm{~nm}$; Figure 7(A)]. For this fluence value, the relief amplitude was strongly influenced by the pulse number. In the case of lower fluence values (20.1 or 17.4 $\mathrm{mJ} / \mathrm{cm}^{2}$ ), the pulse number did not influence the amplitude relief, which remain situated around $200 \mathrm{~nm}$ [Figure 7(B)]. The obtained gratings were split, as in the case of Azo-PCMS, and this reflected similar multistructuration processes.

For fluence values lower than $17 \mathrm{~mJ} / \mathrm{cm}^{2}$, an incomplete relief grating was obtained, but the amplitude was situated around $400 \mathrm{~nm}$ (as shown in Figure 8). This image confirmed the doublestructuration process, as in the case of Azo-PCMS. The SRG stability of the Naph-Azo-Psi could be explained by the higher value of $T_{g}\left(48^{\circ} \mathrm{C}\right)$, which corresponded to this polymer class.

For Naph-Azo-Psi, very good results were obtained, too, for the SRG imprinting with the CW laser irradiation technique $\left(170 \mathrm{~mW} \mathrm{~cm}{ }^{-2}\right.$, irradiation time $\left.=60 \mathrm{~min}\right)$. We observed that in the case of the continuous irradiation technique, much longer times were necessary to obtain the maximum amplitude value. When we compared the doses delivered, in the case of a CW laser illumination, $600 \mathrm{~J} / \mathrm{cm}^{2}$ was necessary to reach the maximum modulation, whereas for pulsed laser illumination, doses between 700 and $3000 \mathrm{~mJ} / \mathrm{cm}^{2}$ enabled 400-nm modulations amplitudes. However, as shown in Figure 9, the relief 
A
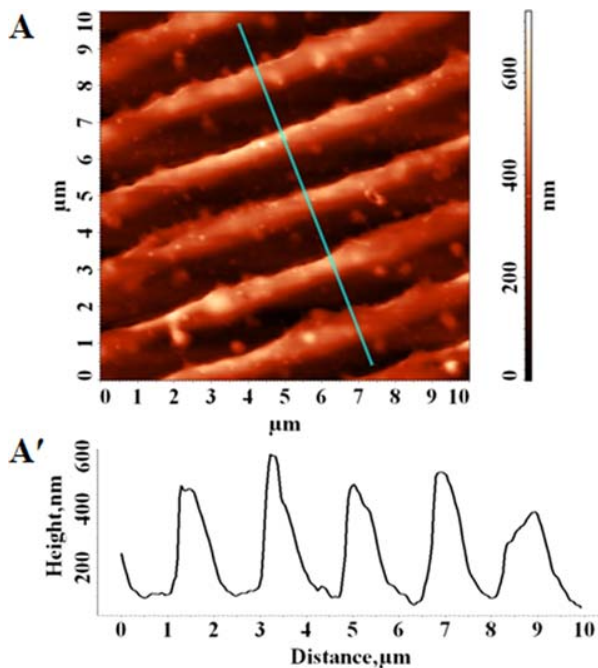

B
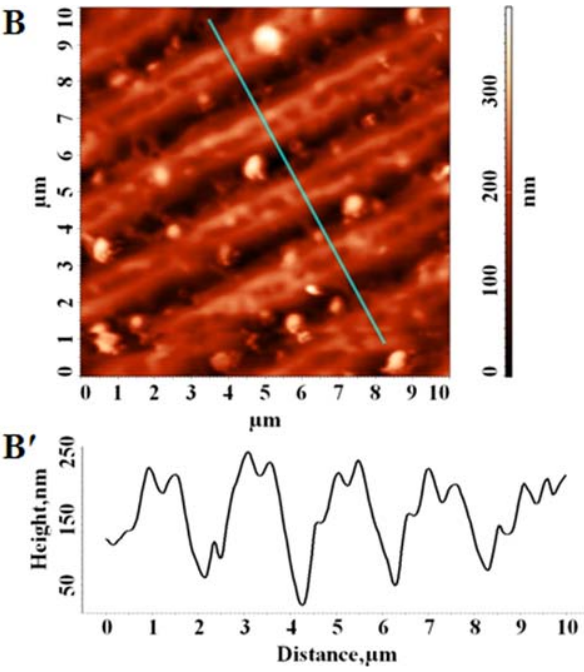

Figure 7. AFM images of the SRGs corresponding to sample 4: (A) laser fluence of $24.5 \mathrm{~mJ} / \mathrm{cm}$ and 30 pulses (relief amplitude $=400 \mathrm{~nm}$ ) and (B) laser fluence of $17.4 \mathrm{~mJ} / \mathrm{cm}$ and 80 pulses (relief amplitude $=200 \mathrm{~nm}$ ). The film thickness was $500 \mathrm{~nm}$, and the SRG periodicity was $2 \mu \mathrm{m}$. [Color figure can be viewed in the online issue, which is available at wileyonlinelibrary.com.]

quality was much better compared with that observed in pulsed laser irradiation. For a film thickness of $700 \mathrm{~nm}$, a $530-\mathrm{nm}$ relief amplitude was obtained.

The next investigated polymer was a polysiloxane substituted with $\mathrm{CF}_{3}$-azobenzene (sample 5). For $\mathrm{CF}_{3}-\mathrm{Azo}-\mathrm{Psi}$, the laser fluence values were $14.0-28.3 \mathrm{~mJ} / \mathrm{cm}^{2}$, and the pulse numbers were between 5 and 250. The results obtained for this sample were comparable with those of Naph-Azo-Psi, with higher amplitudes being obtained for a fluence of $28.3 \mathrm{~mJ} / \mathrm{cm}^{2}$. The

\section{A}
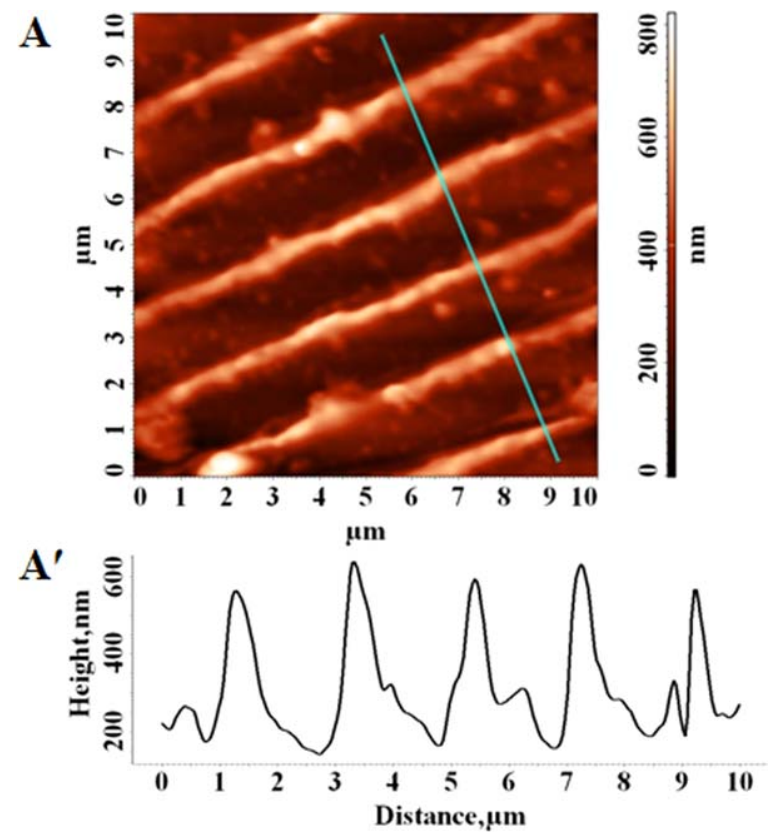

Figure 8. AFM image of the SRGs corresponding to sample 4 with a laser fluence of $15.5 \mathrm{~mJ} / \mathrm{cm}$ and 180 pulses (relief amplitude $=405 \mathrm{~nm}$ ). The film thickness was $500 \mathrm{~nm}$, and the SRG periodicity was $2 \mu \mathrm{m}$. [Color figure can be viewed in the online issue, which is available at wileyonlinelibrary.com.] optimum pulse number was identified to be lower than 25 . As shown in Figure 10(A), with only 20 pulses, amplitude reliefs of higher than $550 \mathrm{~nm}$ were obtained. It must be underlined that an important decrease in the relief amplitude resulted when a higher pulse number of 25 was used, with an SRG amplitude lower than $200 \mathrm{~nm}$ being obtained [Figure 10(B)].

When a comparison was made with pulsed illumination, poorer results were obtained for the $\mathrm{CF}_{3}-\mathrm{Azo}-\mathrm{Psi}$ polymer when a $\mathrm{CW}$ technique was used. As shown in Figure 11, a maximum relief

\section{A}
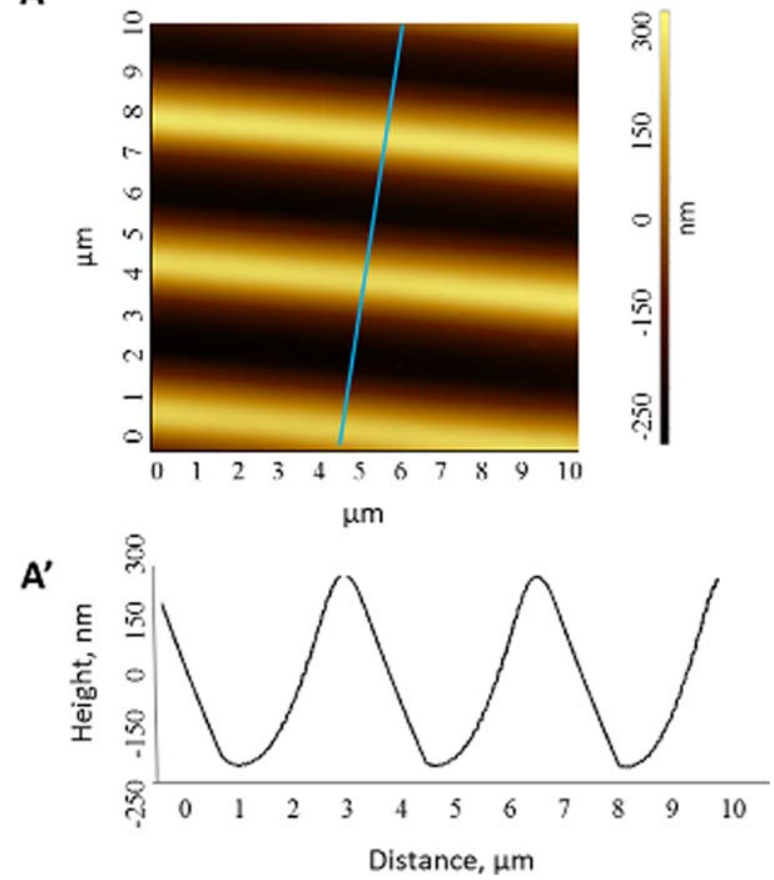

Figure 9. AFM image of the Naph-Azo-Psi film irradiated with a 488-nm laser wavelength (relief amplitude $=530 \mathrm{~nm}, \mathrm{SRG}$ periodicity $=3.6 \mu \mathrm{m}$, film thickness $=700 \mathrm{~nm}$ ). [Color figure can be viewed in the online issue, which is available at wileyonlinelibrary.com.] 
A
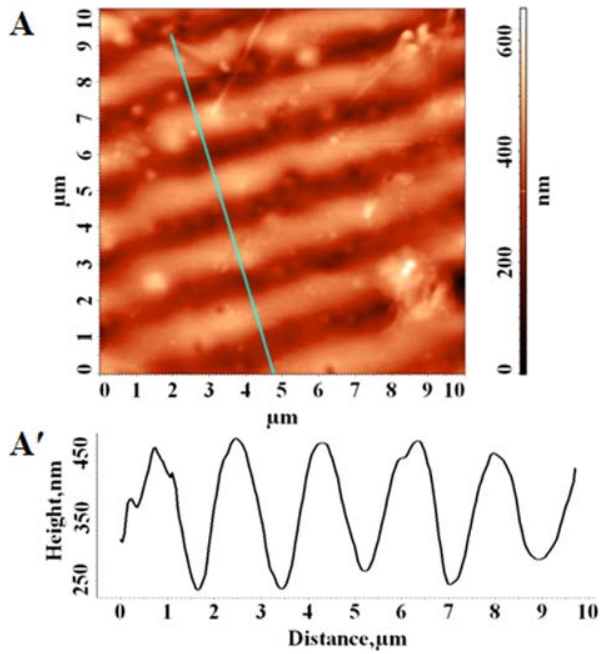

B

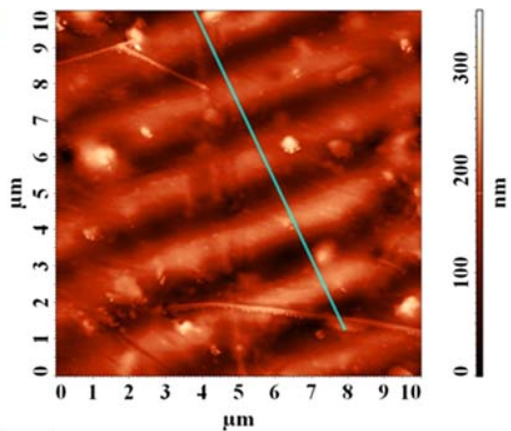

B'

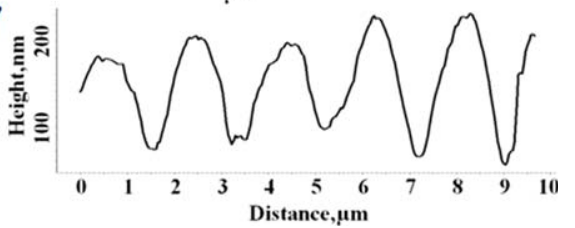

Figure 10. AFM images of the SRGs corresponding to sample 5: (A) laser fluence of $28.3 \mathrm{~mJ} / \mathrm{cm}$ and 20 pulses and (B) laser fluence of $28.3 \mathrm{~mJ} / \mathrm{cm}^{2}$ and 50 pulses. The film thickness was $600 \mathrm{~nm}$, and the SRG periodicity was $2 \mu \mathrm{m}$. [Color figure can be viewed in the online issue, which is available at wileyonlinelibrary.com.]

amplitude of only $55 \mathrm{~nm}$ was obtained after $60 \mathrm{~min}$ of irradiation, and the surface quality was completely irregular. This behavior also indicated a different mechanism for the surface structuration when the films are exposed to a pulsed laser; this was not related to a trans-cis-trans cycling induced mass transport, as described for $\mathrm{CW}$ laser illumination. The process appeared thus to become faster in $\mathrm{CF}_{3}-\mathrm{Azo}-\mathrm{Psi}$ than in the Naph-Azo-Psi polymer, whereas the azo-molecule substitution degree in the first material was lower, and absorption at $355 \mathrm{~nm}$ was similar.

\section{A}
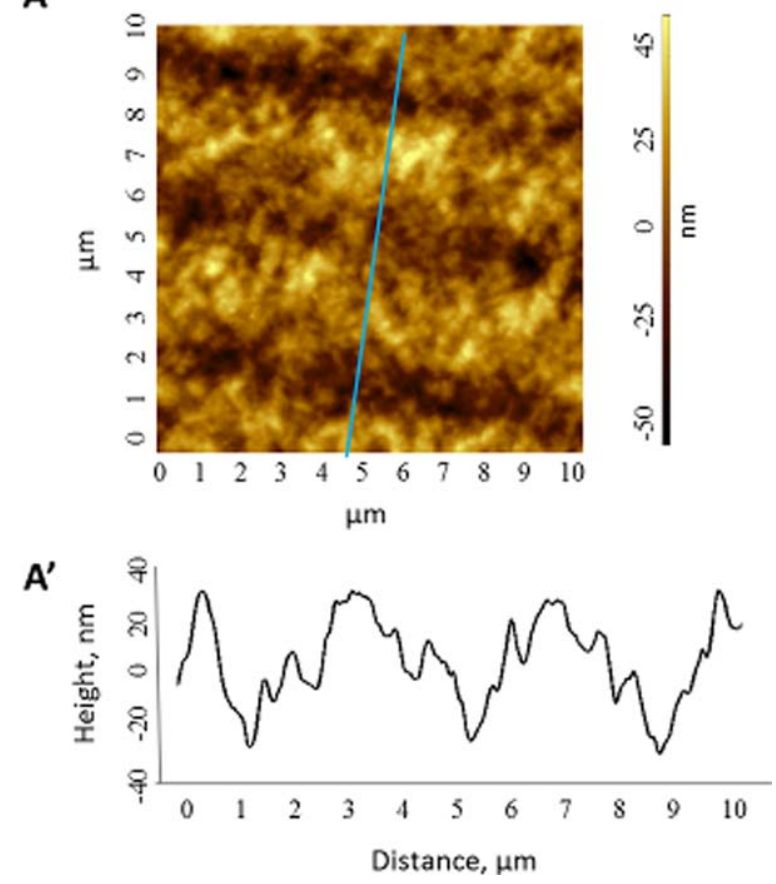

Figure 11. AFM image of the $\mathrm{CF}_{3}-\mathrm{Azo}-\mathrm{Psi}$ film irradiated with a $488-\mathrm{nm}$ laser wavelength (relief amplitude $=55 \mathrm{~nm}, \mathrm{SRG}$ periodicity $=4.3 \mu \mathrm{m}$, film thickness $=740 \mathrm{~nm}$ ). [Color figure can be viewed in the online issue, which is available at wileyonlinelibrary.com.]

\section{CONCLUSIONS}

A comparison of the properties of SRGs induced on azopolymers by pulsed and continuous laser illuminations was performed to show details of the structuration mechanisms involved with each type of illumination. An important conclusion of this study was that the mechanisms corresponding to the SRG formation by pulsed or continuous laser irradiation were different. This conclusion was sustained by the different surface relief stabilities corresponding to pulsed or continuous irradiation and by the surface relief quality. In the case of the Azo-Psi polymer, with the use of a pulsed laser technique, we could not obtain a stable surfaces. By contrast, very stable SRG results occurred when a continuous laser irradiation technique was used.

We proposed an SRG formation mechanism based on a reordering process of the chains at the supramolecular level (as a consequence of the azo groups' trans-cis isomerization); this resulted in material expansion when pulsed illumination was used. As a result, the azopolymer $T_{g}$ value played an essential role in the relief stability. A double-structuration process was evident in the case of the pulse laser irradiation technique.

The pulsed laser irradiated films deformations were more sensitive to the operational conditions (fluence, pulse number, azopolymer structure), with big differences between the SRG qualities being evident for minor modifications of the irradiation conditions.

The azopolymer chemical structure is essential for generating both stable surfaces and good relief quality.

\section{ACKNOWLEDGMENTS}

The Romanian authors thank the National Agency for Scientific Research (ANCS) for its financial support of this research (contract grant number CEA-C1-01/2010, a bilateral French-Romanian project).

\section{REFERENCES}

1. Rochon, P.; Batalla, E.; Natansohn, A. Appl. Phys. Lett. 1995, 66, 136. 
2. Kim, D. Y.; Tripathy, S. K.; Li, L.; Kumar, J. Appl. Phys. Lett. 1995, 66, 1166.

3. Lee, S.; Shin, J.; Lee, Y. H.; Fan, S.; Park, J. K. Nano Lett. 2010, 10, 296.

4. Ambrosio, A.; Marrucci, L.; Borbone, F.; Roviello, A.; Maddalena, P. Nat. Commun. 2012, 3, 989.

5. Fabbri, F.; Garrot, D.; Lahlil, K.; Boilot, J. P.; Lassailly, Y.; Peretti, J. J. Phys. Chem. B 2011, 115, 1363.

6. Labarthet, F. L.; Buffeteau, T.; Sourisseau, C. J. Phys. Chem. B 1998, 102, 2654.

7. Ubukata, T.; Seki, T.; Ichimura, K. Adv. Mater. 2000, 12, 1675.

8. Priimagi, A.; Cattaneo, S.; Ras, R. H.; Valkama, S.; Ikkala, O.; Kauranen, M. Chem. Mater. 2005, 17, 5798.

9. Lee, S.; Kang, H. S.; Park, J. K. Adv. Mater. 2012, 24, 2069.

10. Natansohn, A.; Rochon, P. Chem. Rev. 2002, 102, 4130.

11. Priimagi, A.; Shevchenko, A. J. Polym. Sci. Part B: Polym. Phys. 2014, 52, 163.

12. Ramanujam, P. S.; Pedersen, M.; Hvilsted, S. Appl. Phys. Lett. 1999, 74, 3227.

13. Rodriguez, F. J.; Sanchez, C.; Villacampa, B.; Alcala, R.; Cases, R.; Millaruelo, M.; Oriol, L. Appl. Phys. Lett. 2005, 87, 201914.

14. Miniewicz, A.; Sahraoui, B.; Schab-Balcerzak, E.; Sobolewska, A. M.; Mitus, A. C.; Kajzar, F. Nonlinear Opt. Quantum Opt. 2006, 35, 95.

15. Lee, G. J.; Oh, C. H.; Lee, Y. P.; Kang, I. A.; Han, Y. K. J. Appl. Phys. 2005, 97, 093101.

16. Xiao, S.; Lu, X.; Lu, Q. Macromolecules 2007, 40, 7944.

17. Shimamura, A.; Priimagi, A.; Mamiya, J.-I.; Kinoshita, M.; Ikeda, T.; Shishido, A. J. Nonlinear Opt. Phys. Mater. 2011, 20, 405.

18. Yadavalli, N. S.; Santer, S. J. Appl. Phys. 2013, 113, 224304.

19. Barrett, C. J.; Rochon, P.; Natansohn, A. L. J. Chem. Phys. 1998, 109, 1505.

20. Kumar, J.; Li, L.; Jiang, X. L.; Kim, D.-Y.; Lee, T. S.; Tripathy, S. Appl. Phys. Lett. 1998, 72, 2096.

21. Baldus, O.; Zilker, S. J. Appl. Phys. B 2001, 72, 425.

22. Ambrosio, A.; Maddalena, P.; Marrucci, L. Phys. Rev. Lett. 2013, 110, 146102.

23. Fiorini, C.; Prudhomme, N.; de Veyrac, G.; Maurin, I.; Raimond, P.; Nunzi, J.-M. Synth. Met. 2000, 115, 121.

24. Pedersen, T. G.; Johansen, P. M.; Holme, N. C. R.; Ramanujam, P. S.; Hvilsted, S. Phys. Rev. Lett. 1998, 80, 89.

25. Toshchevikov, V. P.; Saphiannikova, M.; Heinrich, G. J. Chem. Phys. 2012, 137, 024903.

26. Teboul, V.; Saiddine, M.; Nunzi, J.-M.; Accary, J. B. Chem. Phys. 2011, 134, 114517.

27. Juan, M. L.; Plain, J.; Bachelot, R.; Royer, P.; Gray, S. K.; Wiederrecht, G. P. ACS Nano 2009, 3, 1573.

28. Hurduc, N.; Donose, B. C.; Macovei, A.; Paius, C. M.; Ibanescu, C.; Scutaru, D.; Hamel, M.; Branza-Nichita, N.; Rocha, L. Soft Matter 2014. DOI: 10.1039/C4SM00397G.
29. Sava, I.; Rezmerita, A.-M.; Lisa, G.; Damian, V.; Hurduc, N. Polymer 2008, 49, 1475.

30. Hurduc, N.; Enea, R.; Apostol, I.; Damian, V. J. Phys. Conf. Ser. 2008, 100, 012022.

31. Resmerita, A.-M.; Epure, L.; Grama, S.; Ibanescu, C.; Hurduc, N. Open Chem. Biomed. Met. J. 2009, 2, 91.

32. Bruder, F. K.; Hagen, R.; Rolle, T.; Weiser, M.-S.; Facke, T. Angew. Chem. Int. Ed. 2011, 50, 4552.

33. Baac, H. W.; Lee, J.-H.; Seo, J.-M.; Park, T. H.; Chung, H.; Lee, S.-D.; Kim, S. J. Mater. Sci. Eng. C 2004, 24, 209.

34. Barille, R.; Janik, R.; Kucharski, S.; Eyer, J.; Letournel, F. Colloids Surf. B 2011, 88, 63.

35. Hurduc, N.; Macovei, A.; Paius, C. M.; Raicu, A.; Moleavin, I.; Nichita, N.; Hamel, M.; Rocha, L. Mater. Sci. Eng. C 2013, 33, 2440.

36. Takashima, Y.; Hatanaka, S.; Otsubo, M.; Nakahata, M.; Kakuta, T.; Hashidzume, A.; Yamaguchi, H.; Harada, A. Nat. Commun. 2012, 3, 1270.

37. Murugesan, M.; Abbineni, G.; Nimmo, S. L.; Cao, B.; Mao, C. Sci. Rep. 2013, 3, 1820.

38. Ikawa, T.; Kato, Y.; Yamada, T.; Shiozawa, M.; Narita, M.; Mouri, M.; Hoshino, F.; Osamu, W.; Tawata, M.; Shimoyama, H. Langmuir 2010, 26, 12673.

39. Mouri, M.; Ikawa, T.; Narita, M.; Hoshino, F.; Osamu, W. Macromol. Biosci. 2010, 10, 612.

40. Mei, Y.; Saha, K.; Bogatyrev, S. R.; Yang, J.; Hook, A. L.; Kalcioglu, Z. I.; Cho, S. W.; Mitalipova, M.; Pyzocha, N.; Rojas, F.; Van Vliet, K. J.; Davies, M. C.; Alexander, M. C.; Langer, R.; Jaenisch, R.; Anderson, D. G. Nat. Mater. 2010, 9, 768.

41. Weng, S. N.; Fu, J. P. Biomaterials 2011, 32, 9584.

42. Kazmierski, K.; Hurduc, N.; Sauvet, G.; Chojnowski, J. J. Polym. Sci. Part A: Polym. Chem. 2004, 42, 1682.

43. Hurduc, N.; Ades, D.; Belleney, J.; Siove, A.; Sauvet, G. Macromol. Chem. Phys. 2007, 208, 2600.

44. Pawlik, G.; Miniewicz, A.; Sobolewska, A. M.; Mitus, A. C. EPL 2014, 105, 26002.

45. Schab-Balcerzak, E.; Siwy, M.; Kawalec, M.; Sobolewska, A.; Chamera, A.; Miniewicz, A. J. Phys. Chem. A 2009, 113, 8765.

46. Barille, R.; Janik, R.; Kucharski, S.; Eyer, J.; Letournel, F. Colloids Surf. B 2011, 88, 63.

47. Resmerita, A.-M.; Epure, L.; Hurduc, N.; Ades, D.; Siove, A. Macromol. Res. 2010, 18, 721.

48. Sava, I.; Sacarescu, L.; Stoica, I.; Apostol, I.; Damian, V.; Hurduc, N. Polym. Int. 2009, 58, 163.

49. Stoica, I.; Sava, I.; Epure, L.; Damian, V.; Hurduc, N. Microsc. Res. Tech. 2013, 76, 914.

50. Damian, V.; Apostol, I.; Hurduc, N.; Bojan, M.; Udrea, C. Proc. SPIE 2012, 8411, 841128.

51. Raicu Luca, A.; Moleavin, I.; Hurduc, N.; Hamell, M.; Rocha, L. Appl. Surf. Sci. 2014, 290, 172. 